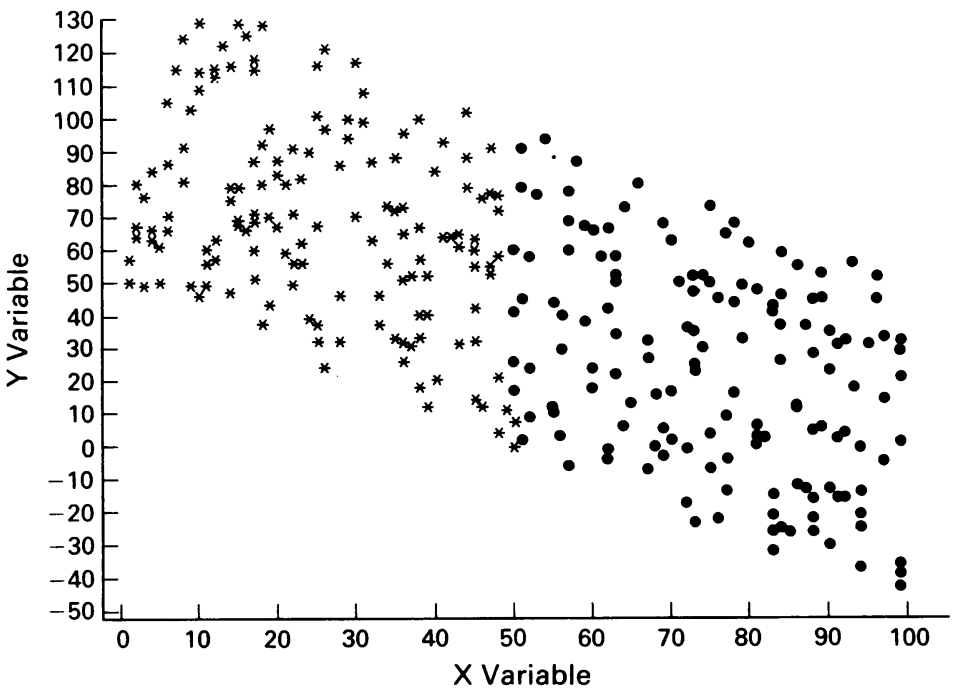

dietary and serum cholesterol is stronger than that between body weight and height.

What is not widely recognised, however, is that $r$ is affected by intersubject variation in the $X$ variable (the standard deviation of the $\mathrm{X}$ variable in the sample, $s){ }^{1}$ This means that the sample correlation $r$ is an unbiased estimate of the population correlation $\rho$ only if $s$ is comparable with the standard deviation of $\mathrm{X}$ in the population $\sigma ; \mathrm{A}$ numeric example is given to show the pronounced dependence of $r$ on $s$.

Based on 300 four digit random numbers that I generated by the SAS software ${ }^{3} \mathrm{I}$ used the first two digits for the $X$ variable and the difference between the last two digits and first two digits plus a constant 50 for $\mathrm{Y}$. Because $\mathrm{Y}$ is part of $\mathrm{X}$, clearly the two variables are correlated. Indeed it can be shown theoretically that $r=0.7$. Next I divided the sample into two subgroups of 150 based on the values of $\mathrm{X}$, subgroup 1 with low $\mathrm{X}$ values and subgroup 2 with high $X$ values (represented by asterisk and solid circle, respectively, in the bivariate appearances, the $r$ value for the subgroups ought to be similar to that for the entire sample. But this is not so (table): $r$ for the entire sample $(-0.68)$ is substantially higher than that for each subgroup $(-0.38$ and -0.42$)$ simply because $s$ is higher in the entire sample (29.0) than it is in the subgroups (14.2 and 14.5). Note that Spearman's rank correlation is similarly affected by $s$. Clearly, these results imply that $r$ is generaliseable only to the population from which the sample was taken, provided the sample is reasonably representative so that $s$ is comparable to $\sigma$, that $r$ should only be compared among different samples provided their $s$ values are similar, and that $r$ based on the entire sample should not be compared with that computed from subsamples. Thus to assess the correlation between age and blood pressure, it would not be valid to scattergram of $\mathrm{Y}$ on $\mathrm{X}$; figure). By all

Mean, standard deviation, and correlations

\begin{tabular}{llllll}
\hline & $n$ & $\bar{X}$ & $s$ & $r$ & $r_{s}$ \\
\hline Entire sample & 300 & 51.0 & 29.0 & -0.68 & -0.68 \\
Subgroup 1 & 150 & 25.6 & 14.2 & -0.38 & -0.33 \\
Subgroup 2 & 150 & 76.0 & 14.5 & -0.42 & -0.39 \\
\hline
\end{tabular}

$\bar{X}=$ mean of $\mathrm{X} ; s=$ standard deviation of $\mathrm{X} ; r=$ product-moment correlation; $r_{\mathrm{s}}=$ Spearman's rank correlation.

compare $r$ for the whole sample with that for hypertensives selected from that sample.

JAMES LEE

Division of Biostatistics and Health Informatics, Department of Community, Occupational and Family Medicine, National University of Singapore, NUH, Lower Kent Ridge Road, Singapore 0511

1 Oldham PD. Measurement in medicine: the interpretation of numeric data. Philadelphia: Lippincott, 1968 (chapter 6).

2 Walker AM, Blettner M. Comparing imperfect measures of exposure. $\mathrm{Am} J$ Epidemiol 1985;121:783-90.

3 SAS language guide, Release 6.03. Cary, North Carolina:SAS Institute, 1988.

\section{Polychlorinated biphenyls: estimated serum half lives}

Sir,-Between 1946 and 1977 two plants of the same company located in upstate New York were manufacturing capacitors using polychlorinated biphenyls (PCBs) with aroclors 1254, 1242 , and 1016 as their primary dielectric fluids. Almost 7000 employees worked there for at least three months during this period. In 1976 a study was started to determine the possible human health effects of exposure to PCBs by detailed examination of a small group of these workers. One hundred and ninety four workers were selected to include employees whose jobs required direct contact with PCB in zones of high air concentration, were in the immediate periphery of the high exposure zone, or had high but intermittent exposure. Health evaluation included a physical examination, chest $x$ ray film, spirometry, haematological and biochemical analyses, urinalysis, and measurement of serum PCB concentrations.' A similar evaluation was conducted in 1979 and - 1983 on participants available for reexamination. Serum determinations were performed by Hazelton Raltech (Madison, Wisconsin) with conventional PCB extraction, and packed column gas chromatography, and were reported as Aroclors 1242, 1254, and $1260 .^{1}$ Because PCBs were still in use at the time of the 1976 evaluation, and because of other uncertainty about the 1976 data, only data from 1979 and 1983 were used in this analysis. Serum PCB determinations were available from both 1979 and 1983 on 148 persons for aroclors 1242 and 1254, 
Table 1 Geometric mean concentrations of PCBs in sera

\begin{tabular}{llrl}
\hline & $\begin{array}{l}\text { No of } \\
\text { volumes }\end{array}$ & 1979 & 1983 \\
\hline $1242(\mathrm{ppb})$ & 148 & 287 & 61 \\
$1254(\mathrm{ppb})$ & 148 & 57 & 25 \\
1260 (ppb) & 121 & 37 & 19 \\
\hline
\end{tabular}

and on 121 persons for aroclor 1260 . These paired measurements formed the basis of our calculations of serum PCB half lives. Table 1 shows the geometric mean PCB concentrations in serum for 1979 and 1983.

Based on the assumption of first order kinetics, we applied linear regression techniques to estimate $k$, the elimination constant, and then determined half lives. The general formula for first order kinetics ${ }^{2}$ is:

$$
\mathrm{X}(\mathrm{t})=\mathrm{X}(\mathrm{o}) \mathrm{e}^{\mathrm{kt}}
$$

where $X(t)=$ concentration at time $t$, $\mathrm{X}(\mathrm{o})=$ initial concentration (time zero), $\mathrm{k}=$ elimination constant (equal to the natural $\log (\ln )$ of 2 divided by the half life, and $t=$ time. Taking $\ln$ of both sides of equation (1), multiplying by -1 , and rearranging gives:

$$
\ln X(0)-\ln X(t)=k t
$$

This can then be analysed by simple linear regression (without an intercept) where the dependent variable $=$ $\ln X(0)-\ln X(t)$ (the difference between the initial and the follow up serum PCB concentrations), $t=48$ months (the time interval between serum measurements), and we solve for $k$. The half life is then estimated as $\ln 2 / \mathrm{k}$.

With this approach, we estimated half lives (and 95\% confidence intervals ( $95 \%$ CIs)) for aroclor 1242 , 1254, and 1260 for all values and separately by quartiles based on 1979 serum concentrations. Table 2 shows the results.

Although PCBs are no longer produced or used in new products in the United States, their long lifespan in existing products, resistance to degradation, widespread contamination of the environment, and lipophilic nature continue to make the question of their safety important for occupational groups with high exposure as well as the general population. Little is known about the elimination of PCBs from humans although recent data indicate that half life varies with initial serum concentration; this suggests an influence of enzyme induction on metabolism. ${ }^{3}$ The overall half lives shown here are in general agreement with those reported by Phillips et al $^{3}$ from another occupationally exposed group where elimination was estimated as 2.6 years for Aroclor 1242 and 4.8 years for Aroclor 1254. Our data also show an effect of initial serum concentration.

Interpretation of data such as these enhance our understanding of the basic metabolism of PCBs in humans and allow important opportunities to improve exposure estimates for studying health outcomes potentially related to exposure to PCBs. ${ }^{45}$

PHILIP R TAYLOR

Department of Health and Human Services, National Institutes of Health, National Cancer Institute, Bethesda, Maryland 20892, USA CHARLES E LAWRENCE New York State Department of Health

1 Lawton RW, Ross MR, Feingold J, Brown JR Jr. Effects of PCB exposure on biochemical and hematological findings in capacitor workers. Environ Health Perspect 1985;60:165-84.

Table 2 Calculated half lives for PCBs

\begin{tabular}{llll}
\hline Aroclor & 1979 Value $(p p b)$ & Half life $(y)$ & $95 \% C I$ \\
\hline 1242 & $0-120$ & $2 \cdot 5$ & \\
& $121-317$ & $1 \cdot 6$ & \\
& $318-553$ & $1 \cdot 8$ & \\
& $554-3133$ & $1 \cdot 5$ & $1 \cdot 7-1 \cdot 9$ \\
1254 & All & $1 \cdot 8$ & \\
& $4-28$ & $4 \cdot 6$ & \\
& $29-54$ & $3 \cdot 1$ & \\
& $55-126$ & $3 \cdot 2$ & \\
1260 & $127-639$ & $2 \cdot 8$ & \\
& All & $3 \cdot 3$ & \\
& $4-18$ & $5 \cdot 7$ & \\
& $19-36$ & $4 \cdot 0$ & \\
& $37-80$ & $4 \cdot 0$ & $3 \cdot 6-4 \cdot 7$ \\
\hline
\end{tabular}

2 Morrow PE. Clearance kinetics of inhaled particles. In: Brain JD, Proctor DF, Reid LM, eds. Respiratory defense mechanisms. New York: Marcel Dekker Inc, 1977:493.

3 Phillips DL, Smith AB, Burse VW, Steele GK, Needham LL, Hannon WH. Half life of polychlorinated biphenyls in occupationally exposed workers. Arch Environ Health 1989;44:351-4.

4 Taylor PR, Lawrence CE, Reilly AA, Stelma JA. Estimating serum polychlorinated biphenyl levels: An empirical model. J Toxicol Environ Health 1991;34:413-22.

5 Taylor PR, Stelma JA, Lawrence CE The relation of polychlorinated biphenyls to birthweight and gestational age in the offspring of occupationally exposed mothers. $A m$ J Epidemiol 1989;129:395-406.

NOTICE

Fourth international conference on education and training in occupational health, Amsterdam, The Netherlands, 24-28 April 1994.

The main theme of the conference will be the establishment, execution, and evaluation of an occupational health and safety programme in an organisation and ways of teaching this.

This conference will be held under the auspices of the Scientific Committee on Education and Training in Occupational Health (of the International Commission on Occupational Health, $\mathrm{ICOH}$ ) and will be organised by the American School of Occupational Medicine. The second announcement will be available by May 1993. For further information contact: P J Kroon, MD, Amsterdam School of Occupational Medicine Corvu, Meibergdreef 15, $1105 \mathrm{AZ}$ Amsterdam. Telephone 20-5664949; Fax 20-6912401. 